\title{
Method to determine particle release during long-term loading for assessment of coating durability of cardiovascular stents
}

\begin{abstract}
Many catheters and vascular implants are coated to increase biocompatibility or to reduce friction during catheter based implantation. Several regulations require assessment of coating durability over the implant's life time. An in vitro method for stent testing is presented to measure released particulate matter at defined inspection intervals. The method was validated using polystyrene microspheres with a size of 10,25 and $50 \mu \mathrm{m}$ to check for particle recovery $(\mathrm{n}=6)$. Two cleaning steps followed. Particle counting was performed by light obscuration method. The recovery rate was $103 \pm 5 \%(10 \mu \mathrm{m}), 94 \pm 4 \%(25 \mu \mathrm{m})$ and $78 \pm 12 \%(50 \mu \mathrm{m})$, respectively, meeting the requirements of FDA guidance documents (i.e. FDA 1545). Less than $3 \%$ of the particles were found in the cleaning solutions. The method using a fixed volume during stent loading can be adapted to all durability testers where tubes are used to fix the stents (radial pulsatile, bending, axial compression, torsion).
\end{abstract}

Keywords: Vascular implants, durability testing, long-term coating integrity, particle release, particle characterization

https://doi.org/10.1515/cdbme-2021-2179

\section{Introduction}

Many catheters and vascular implants are coated to increase biocompatibility or to reduce friction during catheter based implantation. Several regulations require assessment of coating durability during implantation and over the implant's life time. One of the most cited documents was issued by FDA [1] where it is recommended to combine the coating integrity evaluation with delivery, deployment and retraction testing. Testing of this acute coating durability (ACD) is standardized [2].

Since coated drug-eluting stents have entered the field of cardiovascular implants, the long-term coating durability has become an issue. Up to now, several generations of biostable or bioresorbable polymer based and polymer free drug coatings are known on permanent metallic and bioresorbable polymer or metallic stents [3]. Characterization of chronic particulate generation is required i.e. by ISO 25539-2 [4]. The standardization at the American Society for Testing and Materials (ASTM) is currently under development.

There are test setups available which use a closed loop system to permanently flush the stent in a loaded mock vessel continuously measuring particulate matter in the flow (i.e. CDT-series, Dynatek Labs, Galena, MO [5]). Each stent to be tested needs a separate flow circuitry with filters and an online particle counter. While online counting provides detailed information about particle release over time, the setup is quite expensive and prone to counting also gas bubbles of relevant dimensions.

Discontinuous measurement of particle release in a fixed volume is an option, which can be used for various kinds of stent durability testing. Offline particle measurement reduces the effort for particle counting remarkably. Thus, an in vitro method for stent testing is presented to measure released particulate matter at defined inspection intervals.

\section{Material and methods}

\footnotetext{
*Corresponding author: Wolfram Schmidt: Rostock University Medical Center, Institute for Biomedical Engineering, Rostock, Germany, e-mail: wolfram.schmidt@uni-rostock.de Christoph Brandt-Wunderlich, Klaus-Peter Schmitz: Institute for ImplantTechnology and Biomaterials IIB e.V., Rostock, Germany
}

Anja Kurzhals, Niels Grabow: Rostock University Medical Center, Institute for Biomedical Engineering, Rostock, Germany

\subsection{Test setup}

The stents are implanted in clean test tubes filled with particle free test solution (Ampuwa, Fresenius Kabi). The tubes are sealed to avoid contamination. Stent loading is 
applied by the hydraulic pressure in the test chamber. The dynamic pressure amplitude is derived from physiological arterial pressure $( \pm 40 \mathrm{mmHg})$ while the static load on the stent results from the interaction of the over-expanded stent with the vessel wall stress and an additional static hydraulic pressure of $50 \mathrm{mmHg}$ [6]. Then, the fatigue test is started. A schematic drawing of the test setup for pulsatile fatigue testing is shown in figure 1 .

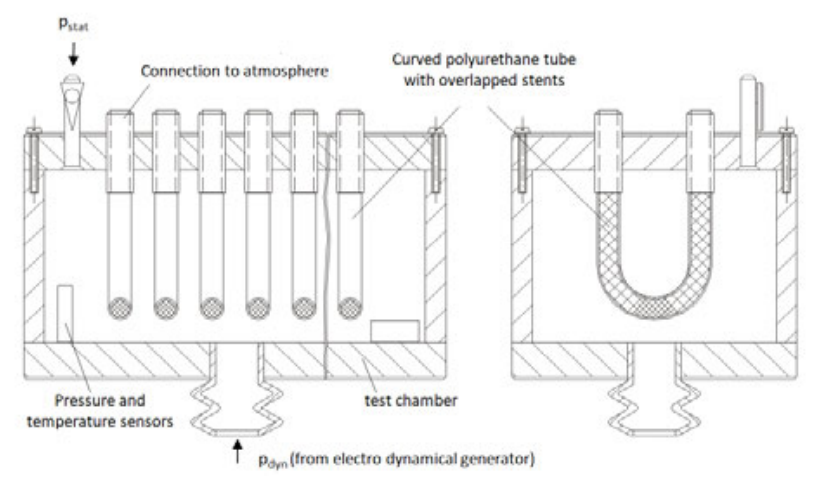

Figure 1: Setup for pulsatile fatigue testing of stents in a bent configuration. For chronic coating durability testing the connection to atmosphere is capped to avoid contamination.

Intermediate and final inspections are performed by pausing the loading, flushing the test tubes and collecting test solution for particulate evaluation (figure 2).

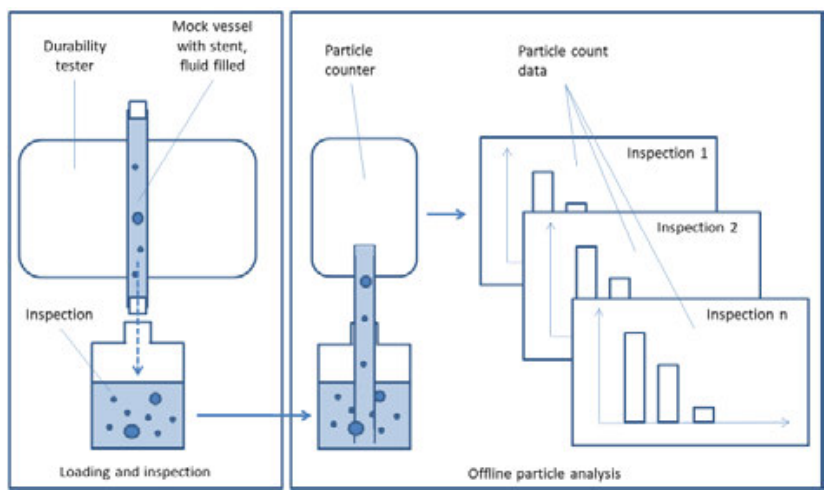

Figure 2: Procedure of chronic coating durability testing with the fixed volume test method. Test fluid with released particulates is collected at given inspection intervals for offline particle counting.

\subsection{Validation tests}

The required validation tests were derived from the analysis of risk factors which possibly influence the size and numbers of released particles. While several factors can be excluded while working in clean room environment, other factors had to be examined experimentally.

As a first condition it should be possible to prepare a particle-free environment for testing. Thus, the particle concentration in the test fluid was measured. The risk of contaminated test solutions is low when using water or saline for injections because such solutions are strictly controlled by the vendor. Nevertheless, reference measurements are obligate for each test.

No particles shall be introduced from the test tubes and connectors which are in contact to the stents and the surrounding test fluid. Thus, the test equipment had to be flushed and the collected solution tested for particles of the size $\geq 10, \geq 25$, and $\geq 50 \mu \mathrm{m}$. The amount of particulate matter in this reference solution should be small compared to the expected particle numbers released during the longterm durability testing.

A spike \& recovery test was performed to check whether all released particles can be collected for offline measurement. A known number of particles was introduced and recollected from the setup. This test had to be done at the specific setup in order to include all sources of error which might be fluid and particle traps or leakage. A test setup for fatigue analysis of coronary stents in a bent configuration (tube $\mathrm{ID}=5 \mathrm{~mm}$ ) was investigated exemplarily (figure 3 ). A volume of $1 \mathrm{ml}$ fluid with polystyrene microspheres of the size of $(10.02 \pm 0.06) \mu \mathrm{m},(24.61 \pm 0.22) \mu \mathrm{m}$, and $(49.30 \pm$ 1.10) $\mu \mathrm{m}$ (COUNT-CAL ${ }^{\text {TM }}$ Count Precision Size Standards, Thermo Scientific) was introduced with a concentration of 3000 particles $/ \mathrm{ml} \pm 10 \%$ to check for particle recovery $(\mathrm{n}=6)$ and removed by flushing. Two cleaning steps followed to measure efficacy of flushing to ensure that all particles were captured and the test equipment is clean for the next procedural step.

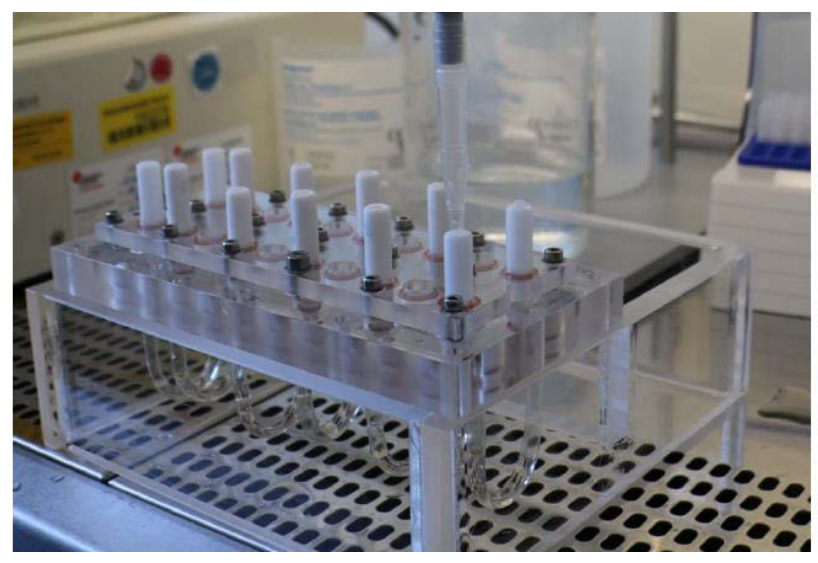

Figure 3: Introduction of count precision size standard microspheres using an Eppendorf pipette $0.1-1.0 \mathrm{ml}$ in a setup of six bent test tubes. 
All particle counting was performed by light obscuration method (HIAC 9703, sensor HRLD-400, Beckman Coulter). This method is well established and standardized for testing of sub-visible particles in aqueous solutions in a pharmaceutical context [7]. Current calibration data were used to confirm the proper function of the counter. The analysed size classes were chosen to cover all introduced particles following table 1 .

Table 1: Chosen particle size classes for detection of recovered particles.

\begin{tabular}{cc}
\hline Nominal particle size & Size class \\
\hline $10 \mu \mathrm{m}$ & $\geq 8 \mu \mathrm{m}$ \\
$25 \mu \mathrm{m}$ & $\geq 15 \mu \mathrm{m}$ \\
$50 \mu \mathrm{m}$ & $\geq 30 \mu \mathrm{m}$ \\
\hline
\end{tabular}

\section{Results}

Both reference solutions, as provided by the vendor and after contact with the cleaned and flushed test setup (test tubes, connectors) contained $\leq 3$ particles $/ \mathrm{ml}$ of the size $\geq 10 \mu \mathrm{m}$.

The number of introduced standard particles was confirmed close to the nominal value of $3000 / \mathrm{ml}$ (table 2). The particles recovered from the setup as well as the much lower numbers of particles from the cleaning runs are also shown (table 2). Figure 4 provides a graphic overview of spike $\&$ recovery test results.

Table 2: Particle numbers as introduced and recovered from the test $\operatorname{setup}(n=6$, mean $\pm S D)$

\begin{tabular}{|c|c|c|c|}
\hline & \multicolumn{3}{|c|}{ Particle size class } \\
\hline & $\geq 10 \mu \mathrm{m}$ & $\geq 25 \mu \mathrm{m}$ & $\geq 50 \mu \mathrm{m}$ \\
\hline \multirow{2}{*}{$\begin{array}{l}\text { introduced } \\
\text { particles }\end{array}$} & 2984 & 2980 & 2993 \\
\hline & \pm 113 & \pm 29 & \pm 47 \\
\hline \multirow{2}{*}{$\begin{array}{l}\text { recovered } \\
\text { particles }\end{array}$} & 3066 & 2805 & 2338 \\
\hline & \pm 135 & \pm 130 & \pm 356 \\
\hline \multirow{2}{*}{$\begin{array}{l}\text { particles in } \\
\text { cleaning run } 1\end{array}$} & 63 & 6 & 44 \\
\hline & \pm 24 & \pm 4 & \pm 16 \\
\hline \multirow{2}{*}{$\begin{array}{c}\text { particles in } \\
\text { cleaning run } 2\end{array}$} & 102 & 8 & 9 \\
\hline & \pm 54 & \pm 10 & \pm 7 \\
\hline
\end{tabular}

The recovery rate defined as the percentage of recovered particles related to the number of introduced particles was $103 \pm 5(10 \mu \mathrm{m}), 94 \pm 4(25 \mu \mathrm{m})$, and $78 \pm 12$ $(50 \mu \mathrm{m})$ (figure 5). The percentage of particles found in the cleaning solutions was $\leq 3 \%$ compared to the reference of 3000 .

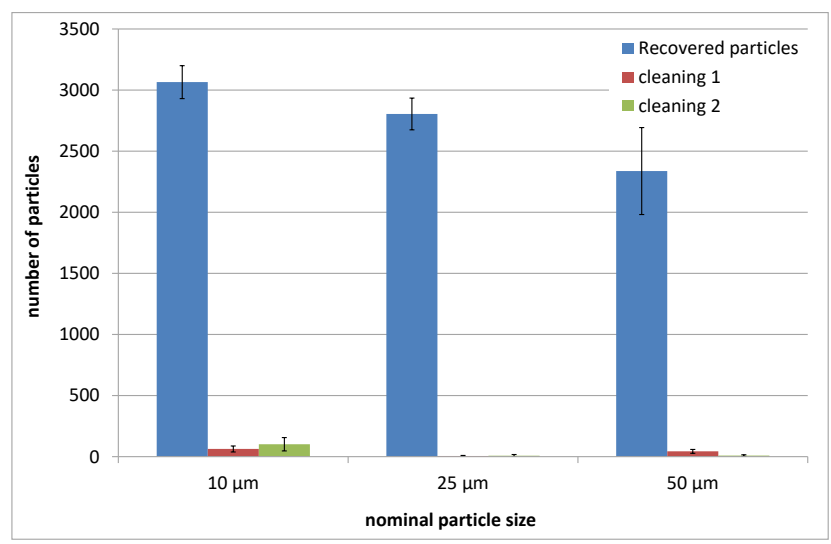

Figure 4: Measured particles after introduction of 3000 particles \pm $10 \%$ (recovered particles) and cleaning runs 1 and $2(n=6$ tests, mean, SD).

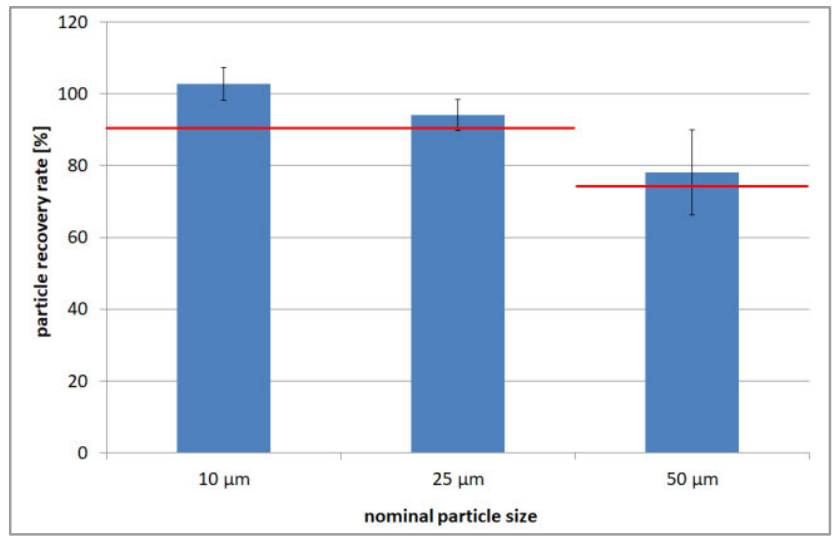

Figure 5: Percentage of recovered particles related to the number of introduced particles (recovery rate, $\mathrm{n}=6$ tests, mean, $\mathrm{SD}$ ). The red lines indicate the minimum requirements of 90 or $75 \%$, depending on the size class of the particles [1]

\section{Discussion}

It was possible to achieve a sufficiently clean and particlefree setup. A particle concentration $\leq 3$ particles / $\mathrm{ml}$ of the size $\geq 10 \mu \mathrm{m}$ was accepted because it is low compared to the number of particles introduced during validation. Due to lacking information on general limits for clinical relevant particle numbers, criteria of pharmaceutical solutions for injections could be considered instead [7]. However, the limits are much higher (6000 particles / $100 \mathrm{ml}$ container) than practically observed at commercially available or filtered water or saline. These criteria are commonly used to 
assess particulate matter generated during simulated use or chronic coating durability testing, but rationales may deviate.

The determined recovery rates meet the requirements of FDA guidance ( $\geq 90 \%$ for $10 \mu \mathrm{m}$ and $25 \mu \mathrm{m}$ particles, $\geq 75 \%$ for $50 \mu \mathrm{m}$ particles). As the cleaning solutions showed only a small number of particles, it is concluded that the cleaning runs are suitably effective. The recovered particles will represent the released amount of particles during stent testing. It is furthermore assumed that the lower recovery rate for the $50 \mu \mathrm{m}$ particles is due to sedimentation. Drop forces result from differences in material density between fluid and particles (about 5\%) and increase for larger particles [8].

Limitations of the test method may occur if the released particles are unstable because they dissolve in the test solution or agglomerate [9]. In these cases material specific investigations are necessary. Time-dependent processes can be controlled choosing appropriate inspection intervals and a defined time-schedule during preparation of test solutions and offline analysis. Quickly dissolving particulate matter may also be of less importance regarding its clinical risk.

The influence of air bubbles erroneously detected as particles can be removed by degassing the test solution before offline analysis. This is a clear advantage compared to the known online measuring test loops.

A specific experimental validation of particle release from stents during fatigue testing is not possible because there is no standard available to compare with.

The test solutions are available for further characterization of particulates by dynamic imaging analysis, scanning electron microscopy or Raman spectroscopy, respectively $[10,11]$. Both last mentioned methods require filtering which can be added using portions of the sampled test fluids.

\section{Conclusion}

Our method using a fixed volume during stent loading can be adapted to all durability testers where tubes are used to fix the stents (radial pulsatile, bending, axial compression, torsion).

The investigated arrangement of tubes and accessories allowed a reproducible particle-free setup, which could be flushed to collect all relevant particulate matter and thus could be used for measurement of particle release during long-term durability testing.

\section{Author Statement}

Research funding: This work was partially funded by the Federal Ministry of Education and Research (BMBF) within the project RESPONSE "Partnership for Innovation in Implant Technology" and the Center of Excellence for Medical Engineering Mecklenburg-Vorpommern.

Conflict of interest: Authors state no conflict of interest. Informed consent, ethical approval: Not applicable

\section{References}

[1] FDA Guidance for Industry and FDA Staff, Non-Clinical Engineering Tests and Recommended Labeling for Intravascular Stents and Associated Delivery Systems (1545), 2010

[2] ASTM F2743-11(2018): Standard Guide for Coating Inspection and Acute Particulate Characterization of Coated Drug-Eluting Vascular Stent Systems, ASTM, 2018

[3] Rykowska, I.; Nowak, I.; Nowak, R. (2020): Drug-Eluting Stents and Balloons-Materials, Structure Designs, and Coating Techniques: A Review. In: Molecules 25 (20). DOI: 10.3390/molecules25204624.

[4] ISO 25539-2:2020: Cardiovascular implants - Endovascular devices - Part 2: Vascular stents, 2020

[5] Dynatek Labs. Particle counting stent tester, https://dynateklabs.com/cdt-20-stent-tester-stent-testing/

[6] Schmidt W, Schmitz K. P. (2007): Devices. In: Lanzer P (Hg.): Mastering Endovascular Techniques - A Guide to Excellence. Philadelphia: Lippincott Williams \& Wilkins, S. 114-135.

[7] US Pharmacopeia: Particulate matter in injections. USP/NF General Chapter <USP 788>. In: U.S. Pharmacopeia, editor Rockville, MD: USP; 2009. National Formulary, USP32-NF27 (Suppl. 2).

[8] Stiess M (2009): Mechanische Verfahrenstechnik Partikeltechnologie 1. 3., vollst. neu bearb. Aufl. Berlin, Heidelberg: Springer Berlin Heidelberg (Spinger-Lehrbuch). Online available at http://site.ebrary.com/lib/alltitles/ docDetail.action?docID=10257925.

[9] Brandt C, Schmidt W, Böhme A, Schmitz K-P (2014): The influence of storage time and degassing of particle solutions on particle counting accuracy. In: Biomed Tech (Berl) 59 (S1), 2-4. DOI: 10.1515/bmt-2014-41.

[10] Kurzhals A, Teske M, Reske T, Eickner T, Grabow N, Schmidt W, Schmitz K-P (2017): Automatic particle analysis by Raman spectroscopy - evaluation of sample preparation and optimum background material. In: Current Directions in Biomedical Engineering 3 (2), S. 707-710. DOI: 10.1515/cdbme-2017-0150.

[11] Kurzhals A, Brandt-Wunderlich C, Grabow N, Schmidt W, Schmitz K-P (2019): Dynamic image analysis of transparent particles released during the simulated use test of cardiovascular devices. In: Current Directions in Biomedical Engineering 5 (1), S. 203-206. DOI: 10.1515/cdbme-20190052. 